\title{
O que é a política cientifica e tecnológica?
}

\author{
BAFAEL DE BRITO DIAS
}

\section{Resumo}

Este artigo pretende explorar uma política pública - a política científica e tecnológica (PCT) - debatendo algumas de suas principais características constitutivas (que a diferenciam significativamente das demais) e procurando evidenciar um de seus aspectos que raramente é explicitado: como política pública elaborada no âmbito do Estado capitalista, a PCT é uma política que favorece às classes dominantes. $\mathrm{O}$ artigo procura entender o porquê desse aspecto nem sempre ser reconhecido. E discorre também sobre algumas das principais causas e implicações disso. Para tanto, são abordados conceitos e definições gerais sobre as políticas públicas. Em seguida, são discutidas as principais características e processos associados à política científica e tecnológica. Também são abordadas as particularidades da PCT brasileira, que denunciam, em grande medida, seu caráter de classe. Por fim, são apresentados argumentos que se propõem a explicar o porquê desse caráter ser raramente reconhecido.

Palavras-chave: Política científica e tecnológica. Políticas públicas. Estado capitalista. Comunidade de pesquisa. Brasil.

* Doutor em Política Científica e Tecnológica (DPCT/UNICAMP) e professor da Faculdade de Ciências Aplicadas Universidade Estadual de Campinas - UNICAMP. 


\section{Introdução}

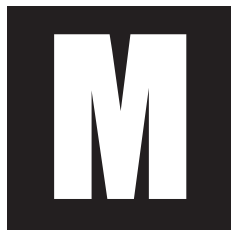

uitos dos autores contemporâneos que se dedicam ao estudo do tema das políticas públicas compartilham da ideia de que é cada vez mais importante entender suas características e a dinâmica dos processos a elas associados. Reflexões desse tipo permitem, entre outras coisas, o aprimoramento das políticas públicas e uma melhor compreensão acerca da própria natureza do Estado, além de constituírem uma contribuição para o fortalecimento da democracia e da cidadania.

Apesar de a política científica e tecnológica (ou PCT) apresentar uma importância crescente em diversos países (ao menos em termos do discurso dos atores com ela envolvidos), sendo frequentemente apontada como estratégica para a promoção do desenvolvimento nacional, os estudos que dela se ocupam ainda parecem carecer de certos cuidados em termos conceituais.

Essa percepção é particularmente válida no caso dos países latinoamericanos. Os estudos acerca da política científica e tecnológica na região, associados a uma tradição importante que teve como expoentes nomes como Amílcar Herrera, Jorge Sábato, Oscar Varsavsky, José Leite Lopes e Francisco Sagasti, têm sido cada vez mais orientados por conceitos e métodos oriundos dos países ditos "desenvolvidos". É particularmente notável, por exemplo, a crescente influência da Economia da Inovação nas reflexões sobre a PCT, tanto no âmbito acadêmico quanto naquele da elaboração de políticas públicas.

Em grande parte, isso ocorre porque a política científica e tecnológica constitui um caso especial dentre o conjunto das políticas públicas. Devido à concepção comum em torno da neutralidade e do determinismo da ciência e da tecnologia (C\&T), as quais se condensam sob a forma 
de uma visão triunfalista e essencialista, os aspectos ideológicos e políticos intrínsecos à PCT são ocultados. Desse modo, as reflexões teóricas comumente realizadas a respeito desse objeto - a política científica e tecnológica - tendem a ignorar essas questões. É precisamente da percepção dessa carência que parte este artigo.

Com base em reflexões de autores associados a uma perspectiva crítica, o presente artigo busca fornecer elementos que possam estimular questionamentos a respeito da natureza dessa política pública. Em particular, pretende-se evidenciar um aspecto que raramente é reconhecido: como qualquer política elaborada no âmbito do Estado capitalista, a PCT é também uma política que atende aos interesses de um determinado conjunto de atores sociais (ou de uma classe social específica). Cabe aqui, entretanto, uma advertência: embora reconheçamos que, evidentemente, os aportes do pensamento marxista em muito pudessem contribuir para essa análise, são empregados de forma superficial neste trabalho. Isso porque este artigo está mais orientado a leitores envolvidos com reflexões críticas sobre a PCT do que propriamente àqueles familiarizados com a Teoria Marxista.

O artigo está dividido em quatro itens, além desta introdução. O primeiro deles apresenta algumas considerações de caráter mais geral acerca da natureza das políticas públicas, destacando, em particular, seu significado no âmbito do Estado capitalista. O segundo discute conceitos gerais, definições e as principais características da política científica e tecnológica. O terceiro item traz algumas das especificidades dessa política em contextos periféricos e, em particular, no Brasil. Além disso, fornece alguns argumentos que se propõem a explicar o porquê do "caráter de classe" da PCT ser raramente reconhecido. Por fim, o quarto item expõe as principais considerações que foram derivadas da argumentação construída ao longo deste artigo. 


\section{Políticas públicas no Estado capitalista}

A forma com que se entende uma política pública está diretamente relacionada com a percepção que se tem do Estado. Frequentemente compreende-se a política pública como uma ação ou conjunto de ações por meio das quais o Estado interfere na realidade, geralmente com o objetivo de atacar algum problema. Essa definição se mostra um tanto quanto simplista, uma vez que trata o Estado como um ator que opera de forma autônoma e beneficia a sociedade como um todo através de suas ações.

Em um expressivo esforço de sistematização e detalhamento de conceitos referentes ao Estado e a políticas públicas, Souza (2006) resgata as contribuições dos principais autores que se dedicaram ao estudo desses temas. Para a autora,

Não existe uma única, nem melhor, definição sobre o que seja política pública. Mead (1995) a define como um campo dentro do estudo da política que analisa o governo à luz de grandes questões públicas e Lynn (1980), como um conjunto de ações do governo que irão produzir efeitos específicos. Peters (1986) segue o mesmo veio: política pública é a soma das atividades dos governos, que agem diretamente ou através de delegação, e que influenciam a vida dos cidadãos. Dye (1984) sintetiza a definição de política pública como "o que o governo escolhe fazer ou não fazer". A definição mais conhecida continua sendo a de Laswell, ou seja, decisões e análises sobre política pública implicam responder às seguintes questões: quem ganha o quê, por quê e que diferença faz. (p. 24)

É justamente nas contribuições de Dye e de Laswell que nos apoiamos em nossa argumentação. De fato, a definição proposta por Dye (1984) a torna particularmente aderente ao que se observa na realidade. Políticas públicas não devem ser entendidas apenas como o que o Estado faz (sua dimensão mais facilmente percebida), mas também como aquilo 
que ele deixa de fazer. Suas ações - ou inações - refletiriam os comportamentos dos atores que nele atuam.

A definição proposta por Laswell (1958) é particularmente interessante, pois gera uma reflexão acerca de questões absolutamente pertinentes em relação às políticas públicas. Sendo essas geradas no âmbito do Estado capitalista, as respostas a essas perguntas - e em particular para parte da primeira ("quem ganha") - bem poderiam apontar para a classe dominante.

Afinal, o Estado capitalista é, simultaneamente, um produto da estrutura de classes das sociedades capitalistas e a entidade que garante a preservação dessa estrutura (O'Donnell, 1981). Na esfera do Estado estão inseridos atores que dispõem de interesses, valores, ideologias e projetos políticos distintos. O Estado é um ambiente de sistemática disputa política. Não deve, portanto, ser compreendido como um ente independente da sociedade e imune aos conflitos que nela se manifestam.

Ham \& Hill (1993) oportunamente lembram que as análises dos processos políticos devem levar em conta que estes ocorrem no seio do "Estado capitalista moderno" (o que chega a ser redundante, pois todo Estado capitalista é também moderno). Essa simples constatação nos traz um elemento importante para a argumentação que aqui pretendemos construir. Ora, se as características do contexto social influenciam os processos políticos dentro e ao redor do Estado, e se este é capitalista, é evidente que os conflitos entre classes sociais, típicos das sociedades capitalistas, também se manifestarão na esfera do Estado.

Essa noção não é nova. Pelo contrário: ela tem sido abordada por diversos autores, cujas análises englobam políticas públicas das mais diversas. Ela aparece, de forma implícita ou explícita, em trabalhos de autores como Offe (1994), Sposati (1997), Faleiros (2000), Brugué (2004) e Thwaites Rey (2008), para citar apenas alguns. 
De modo geral, a visão marxista entende as políticas públicas como instrumentos por meio dos quais a classe dominante mantém a estrutura de dominação econômica e política da qual se beneficia. Nesse sentido, as políticas devem ser entendidas como resultados de determinantes superestruturais associados ao próprio sistema capitalista.

A relação entre Estado e políticas públicas é, portanto, dinâmica. Autores como O'Donnell (1981), partindo da abordagem marxista, fornecem elementos para a compreensão dessa relação. Se, inequivocamente, o Estado capitalista conforma um padrão particular de políticas públicas, ele é também por elas influenciado. A sucessão de agendas de diferentes governos configura o "mapa" do Estado. Nesse mesmo sentido, as políticas públicas, segundo Oszlak e O’Donnell (1995), apresentariam um importante caráter dual. Ao mesmo tempo em que geram processos externos ao Estado, geram também processos internos a ele.

Ainda na visão de Oszlak e O'Donnell (1995), é possível afirmar que uma política estatal não constitui nem um ato nem um reflexo de uma resposta isolada, mas sim um conjunto de iniciativas e respostas que permitem inferir a posição do Estado frente a uma determinada questão. Assim, as políticas estatais podem ser classificadas como "nós" do processo social, na medida em que refletem as diversas interações (inclusive disputas) entre os atores sociais.

De forma despretensiosa, podemos afirmar que as políticas públicas são o Estado em movimento. Não são, evidentemente, as únicas formas de ação estatal. Mas constituem, sem dúvida, aquela forma que melhor reflete a natureza do Estado capitalista. Não é trivial, portanto, que tanta atenção tenha sido despendida pelos analistas de políticas públicas ao momento da definição da agenda (Ham \& Hill, 1993; Rochefort \& Cobb, 1994; Roth Deubel, 2006). 
A agenda é, justamente, o instrumento que reflete a priorização de temas e problemas a serem trabalhados por um governo (Roth Deubel, 2006). Precisamente devido a essa característica, a agenda é o espaço disputado entre os diversos atores que fazem parte do jogo político. É a particular arquitetura de poder existente em cada situação que irá determinar quais os temas que deverão compor a agenda e quais aqueles que não serão contemplados. E, como mostrou Lukes (1974) por meio da proposição do conceito de "conflitos latentes", isso nem sempre ocorre de forma facilmente reconhecível.

São, sobretudo, esses conflitos que viabilizam a blindagem da agenda por parte dos atores dominantes, não permitindo que as demandas e os projetos dos demais sejam incorporados a ela. Trata-se de um processo relativamente frequente nas políticas públicas, e particularmente comum na PCT, conforme discutimos posteriormente neste artigo.

Os elementos que apresentamos até aqui, embora não tenham de forma alguma sido debatidos com o grau de profundidade que sua própria complexidade demanda, são úteis para a argumentação que desenvolvemos nos itens que seguem. Em particular, não nos parece ser possível que efetivamente se compreenda o significado - político, inclusive - de um determinado curso de ação ou inação estatal sem que se considere o fato do Estado capitalista não ser um ator politicamente neutro.

Especificamente quando se analisa o objeto que aqui nos interessa (a política científica e tecnológica), contudo, as implicações desse caráter de classe não raro são ignoradas. Há que se explorar as principais características dessa política para que se possa entender o porquê disso.

\section{Política científica e tecnológica}

A política científica e tecnológica (ou, simplesmente, PCT) constitui um objeto de estudo extremamente complexo e que possibilita uma 
ampla variedade de recortes. Programas de pesquisa, instrumentos de financiamento, instituições, aspectos da legislação e a dinâmica de geração de conhecimento e de inovações são exemplos de apenas alguns temas que compõem o escopo dessa política. Essa complexidade, naturalmente, impõe determinados obstáculos metodológicos que não podem ser ignorados. Nesse sentido, a análise que desenvolvemos ao longo deste item, embora remeta, em alguns momentos e apenas a título de ilustração, a aspectos mais pontuais da política científica e tecnológica, tem seu foco nas características mais gerais dessa política.

Optamos por tratar, de fato, de duas políticas - a científica e a tecnológica - por dois motivos. O primeiro deles, de caráter teórico-metodológico, está baseado em uma ponderação levantada por uma série de autores do campo dos Estudos Sociais da Ciência e da Tecnologia, de acordo com a qual a ciência estaria se tornando cada vez mais tecnológica e a tecnologia, mais científica. Essas duas dimensões estariam tão estreitamente ligadas que seria impossível detectar a fronteira que as separa, inclusive no plano das políticas públicas. O segundo motivo é de caráter prático: no Brasil, o conjunto de ações federais para a área de C\&T é reconhecido como política científica e tecnológica. Do mesmo modo como essas ações tratam ciência e tecnologia de forma integrada, também o fazemos neste estudo.

A política científica pode ser compreendida como o produto da tensão existente entre "a agenda da ciência" - o conjunto de interesses relativamente articulados da comunidade de pesquisa - e "as agendas da sociedade", que envolvem uma grande pluralidade de atores e interesses. Em relação a esse aspecto, Smith (1990) afirma que

os cientistas sempre serão os maiores interessados nas atividades científicas e nas circunstâncias que afetam o progresso da ciência. Apesar de, com frequência, se interessarem intensamente pela política (da mesma forma como não-cientistas se interessam pela ciência), os cientistas refratam os temas através de suas perspectivas disciplinares e profissionais (p. 13). 
A definição apresentada por Neal, Smith e McCormick (2008) é, em grande medida, complementar a essa, focando mais nos aspectos legais e regulatórios da política do que no papel dos atores que dela participam. De acordo com os autores, a política científica é referente ao conjunto de leis, regras, práticas e orientações sob as quais a pesquisa científica é conduzida. Além disso, envolve as condições que afetam como esse arcabouço legal-regulatório é desenhado e implementado. A exemplo de outras políticas, complementam os autores, a política científica quase nunca assume uma lógica racional, sendo, na maioria dos casos, incremental e difusa. Essa característica, contudo, é encoberta pela percepção, bastante difundida, de que o conhecimento científico avança de forma autônoma em relação à sociedade.

Avançando nessa definição, Neal, Smith e McCormick (2008) sustentam que:

idealmente, a política científica deveria apoiar as necessidades dos cidadãos e se intrometer na condução da pesquisa científica apenas quando isso leva a uma melhoria do bemestar público. Ademais, ela não deve interferir quando tal ação pode limitar o progresso da ciência sem que haja uma concomitante redução do risco público (p. 9).

Com efeito, essa concepção parece ser compartilhada por muitos policy makers e acadêmicos envolvidos com a política científica e tecnológica. É preciso, no entanto, ressaltar que, como qualquer política pública elaborada no âmbito do Estado capitalista, a PCT atende fundamentalmente aos interesses de alguns atores sociais: da comunidade de pesquisa e, em menor medida, da burguesia industrial nacional, no caso brasileiro.

Ademais, como discutimos anteriormente, ao analisarmos uma política pública, é preciso evitar trabalhar com categorias cujo significado pode mascarar relações de poder, como aquelas inspiradas pela concepção pluralista. Afinal, frequentemente expressões como "desenvolvimento nacio- 
nal" ou "bem-estar social" são empregadas para qualificar processos que favorecem exclusivamente a classe dominante ou os atores mais poderosos.

Continuando nessa linha de argumentação, convém destacar que é da particular arquitetura de poder conformada pelos atores que participam do "jogo político" em cada momento histórico que a política pública é moldada. Assim, a política científica e tecnológica - nosso objeto de análise pode adotar diferentes orientações (militar, desenvolvimentista, para competitividade, para o desenvolvimento sustentável, para a inclusão social, etc.), as quais refletem, justamente, o resultado desse "jogo". Conforme argumentaremos ao longo deste trabalho, a PCT apresenta uma importante particularidade: o fato da arquitetura de poder do "jogo" político pender fortemente em favor da comunidade de pesquisa, seu ator dominante.

Entendemos a comunidade de pesquisa como o conjunto de profissionais envolvidos com atividades científicas, tecnológicas e acadêmicas em geral. Trata-se de um grupo heterogêneo de indivíduos e instituições que, em geral, compartilham de valores, interesses, ideologias e práticas profissionais bastante próximas, o que permite que seja tratado, sem prejuízos significativos, como uma categoria de análise específica.

A despeito da pouca atenção que recebe em relação a outras políticas (inclusive, no caso brasileiro, em termos de orçamento), a PCT representa um instrumento fundamental dentro do escopo das políticas públicas. Em relação a esse ponto, convém resgatar as ideias de Edelman (1985), para quem a política científica e tecnológica é singular porque compreende muito mais do que a simples alocação de recursos públicos: envolve também a moldagem das formas com que as pessoas interpretam socialmente quem são e o que é real e importante, por meio do conhecimento científico e tecnológico.

A política científica e tecnológica é geralmente tratada em conjunto (e até mesmo sem o devido cuidado para com a distinção conceitual) com a política industrial e com a política de inovação. A falta de clareza 
conceitual nesse sentido guarda, naturalmente, uma estreita relação com os argumentos que apresentamos posteriormente neste trabalho: tratar a PCT como sinônimo da política industrial é uma imprecisão.

Nesse sentido, é preciso destacar a relação estreita que é estabelecida, com frequência, entre a política científica e tecnológica e a política industrial. Erber (2006), por exemplo, classifica essas duas políticas como "gêmeas xifópagas". Essa ambiguidade acaba por subestimar a abrangência da política científica e tecnológica, uma vez que implicitamente destaca o papel das empresas em detrimento dos outros atores sociais envolvidos com essa política (universidades e institutos públicos de pesquisa, movimentos sociais, ONGs, etc.).

Para Salomon (1970), a política científica (e, por extensão, tecnológica) representa o conjunto de medidas governamentais que visam simultaneamente apoiar as atividades de pesquisa científicas e tecnológicas e explorar seus resultados de acordo com objetivos políticos gerais. Assim, essa política é, de acordo com o autor, determinada pela ideia de uma integração deliberada entre atividades científicas e tecnológicas, de um lado, e de decisões de caráter social, político, econômico e militar, de outro.

Assim, convém atentar para outra especificidade da política científica e tecnológica. Ao contrário das demais políticas, essa parece ser mais facilmente capturada por interesses particulares, mais especificamente aqueles da própria comunidade de pesquisa, sem que isso seja, contudo, percebido com facilidade.

Uma importante particularidade da política científica e tecnológica, nem sempre reconhecida, remete a seu caráter de política-meio. Como tal, a PCT constitui, ao menos idealmente, um suporte para as demais políticas públicas como, por exemplo, industrial, agrícola, de educação, de saúde, de inclusão social, etc. Embora tenha objetivos próprios, esses constituem elementos de uma estratégia maior, geralmente atrelados a 
outras políticas. Essa característica parece ter sido abandonada no caso da PCT brasileira, a exemplo do que também se verifica em outros casos nacionais, levando a crer que se trata de um processo condicionado por fatores mais amplos. Com efeito, o que se percebe é que, sobretudo nas últimas duas décadas, a promoção de inovações tecnológicas tem, gradualmente, sido tratada como a finalidade máxima dessa política, alterando, assim, a própria identidade da PCT.

Apresentadas as principais características da política científica e tecnológica, convém delinear os aspectos associados a seu surgimento e institucionalização, geralmente associados ao famoso relatório Science: the Endless Frontier, preparado pelo então diretor da Agência de Pesquisa Científica e Desenvolvimento (Office of Scientific Research and Development) norteamericana, Vannevar Bush. O relatório foi elaborado a pedido do presidente Franklin D. Roosevelt e entregue a seu sucessor, Henry Truman, em 1945. Na prática, o relatório "codificou a racionalidade para o apoio governamental às atividades de pesquisa e desenvolvimento ( $\mathrm{P} \& \mathrm{D})$ no pós-2 ${ }^{\mathrm{a}}$ Guerra Mundial" e, ao fazê-lo, "criou uma base retórica para explicar o valor da ciência e da tecnologia na sociedade moderna" (Sarewitz, 1996, p. 17). Através desse relatório, a comunidade de pesquisa norte-americana, representada por Vannevar Bush, buscou garantir que assuntos ligados à ciência e à tecnologia recebessem, em tempos de paz, a mesma atenção que haviam recebido durante a $2^{2}$ Guerra Mundial.

Codificando a racionalidade da sociedade norte-americana da época, o relatório teve um significativo impacto no que se refere à consolidação do apoio sistemático do Estado às atividades de ciência e tecnologia. Ao mesmo tempo, criou uma base retórica sobre a qual foi apoiada a concepção sobre ciência e tecnologia que permeia a sociedade contemporânea.

De fato, a preocupação em relação à estruturação das políticas públicas nessa área ganhou um tremendo impulso após a publicação do 
relatório de Vannevar Bush. Conforme destaca Salomon (1999), muitos países aumentaram os recursos destinados à promoção do avanço científico e tecnológico, aumentaram a quantidade e a qualidade de seus pesquisadores, de seus laboratórios e de suas instituições de ensino e implementaram novos programas de pesquisa, seguindo o receituário proposto no Relatório. Segundo Kraemer (2006), o gasto do governo federal norteamericano com o apoio a atividades de P\&D, por sua vez, aumentou em quase seis vezes, passando de US\$ 6,2 bilhões, em 1955, para US\$35,9 bilhões, em 1970 (em valores correntes de 2006).

De acordo com Sarewitz (1996), essa racionalidade pode ser sintetizada a partir de cinco pressupostos fundamentais amplamente aceitos, embora não verdadeiros, em relação à ciência:

- Benefício infinito: referente à crença de que "mais ciência inevitavelmente levaria a um aumento do bem-estar social". Esse argumento, embora amplamente aceito pela sociedade (e intensamente advogado por uma parcela da comunidade de pesquisa), não está, segundo o autor, apoiado sobre qualquer base racional.

- Pesquisa livre: ideia segundo a qual qualquer linha de pesquisa razoável voltada para a compreensão de processos fundamentais da natureza renderá benefícios para a sociedade. A ciência teria uma lógica intrínseca de funcionamento, que garante que os problemas a serem por ela trabalhados são apresentados por questões técnicas, e não sociais.

- Responsabilidade: os mecanismos de controle da qualidade da pesquisa científica (como a revisão por pares e a fidelidade ao método científico, por exemplo) conteriam as principais responsabilidades éticas do sistema de pesquisa. Assim, todo e qualquer conhecimento gerado dentro desse sistema de normas seria, necessariamente, ético. 
- Autoridade: a informação científica oferece uma base estritamente objetiva para a resolução de disputas políticas. A valorização da ciência sobre todas as outras formas de conhecimento, portanto, conferiria inquestionável legitimidade à opinião dos cientistas.

- Autonomia: o conhecimento gerado na "fronteira" da ciência seria autônomo em relação a suas consequências práticas e morais junto à sociedade. O avanço científico, portanto, seria um fenômeno quase natural, ao qual a sociedade deve se adaptar.

De forma muito similar, Bimber e Guston (1995) afirmam que a visão de ciência e tecnologia que apresenta a comunidade de pesquisa é pautada pelas concepções do universalismo, do essencialismo e do triunfalismo (os três grandes "ismos" da C\&T), o que explica, em grande medida, as características da política científica e tecnológica, dominada por esse ator social. Pode-se ainda imputar a racionalidade da comunidade de pesquisa à visão da neutralidade da C\&T.

Nessa direção, os autores argumentam que a interpretação acadêmica acerca da ciência (e da tecnologia) e de suas relações para com o Estado denuncia as persistentes percepções codificadas pelo relatório de Vannevar Bush, situando a política científica (e tecnológica) em uma categoria completamente dissociada daquela da ciência, ainda frequentemente entendida como a nobre e desinteressada busca pela verdade objetiva por trás do mundo natural.

No sentido de derrubar a blindagem ideológica que envolve a PCT, os autores questionam o "excepcionalismo científico", apoiado em quatro postulados fundamentais:

- excepcionalismo epistemológico: ciência como a busca pela verdade; 
- excepcionalismo platônico: ideia de que somente um grupo restrito de pessoas de intelecto privilegiado deve ficar responsável pela condução do processo político;

- excepcionalismo sociológico - ciência tem uma ordem normativa única que garante seu bom funcionamento (como coloca a noção mertoniana das normas institucionalizadas);

- excepcionalismo econômico - ciência constitui um investimento produtivo que possibilita um extraordinário retorno futuro.

Apesar de reconhecerem que os três primeiros postulados, ao menos naquilo que se refere ao campo dos Estudos Sociais da Ciência e da Tecnologia, têm sido atacados ao longo das últimas décadas, os autores admitem que o último deles - o excepcionalismo econômico - ainda permanece pouco contestado.

Talvez uma das mais robustas críticas a essa noção seja aquela apresentada por Salomon e Lebeau (1993). Segundo os autores, a imagem socialmente aceita da ciência é construída por atores dos países desenvolvidos, incluindo agências públicas, laboratórios, universidades e empresas. Inerentemente elitista, essa concepção acaba por influenciar as próprias práticas científicas e tecnológicas, inclusive nos países subdesenvolvidos.

Mais do que simples fatores que condicionaram a institucionalização da política científica e tecnológica nos países avançados, os elementos apresentados anteriormente configuram a própria essência dessa política até os dias atuais. Ao longo das seis décadas que se passaram desde a elaboração do relatório Science: the Endless Frontier, essa visão acerca do avanço da ciência (e também da tecnologia) - associada à racionalidade ou ao sistema de crenças de seu ator central, a comunidade de pesquisa - tem influenciado e legitimado as ações adotadas no âmbito da PCT, tanto nos países centrais quanto nos periféricos. Tem, ademais, favorecido de forma considerável a esse ator, sobretudo quando observamos o que ocorre no Brasil e em outros países da América Latina. 


\section{As especificidades da política científica e tecnológica brasileira}

A política científica e tecnológica brasileira tem sido amplamente discutida, a partir de perspectivas diferentes (embora, em muitos aspectos, complementares), ao longo das últimas décadas. Tem sido objeto de análises focadas, por exemplo, em processos históricos (Morel, 1979; Fernandes, 1990; Motoyama et al., 2004; Viotti, 2008), nas relações políticas entre atores sociais (Velho, Velho \& Sáenz, 2004; Dagnino, 2007; Baumgarten, 2007), em aspectos operacionais, prospectivos e propositivos (Corder \& Salles Filho, 2004; Schwartzman, 2008) e enquanto campo de reflexão que poderia ser enriquecido por meio de aportes oriundos das ciências humanas e sociais (Maciel, 2005; Sobral, 2007). Contribuições diversas, como as citadas anteriormente, contribuem para uma interpretação crítica do significado político das ações conduzidas no contexto da PCT.

É fundamental compreender os principais marcos na trajetória dessa política à luz dos processos mais amplos que paralelamente ocorriam. Nesse sentido, a institucionalização da política científica e tecnológica no Brasil, marcada pela criação da CAPES e do CNPq (Morel, 1979), deve ser entendida como um processo que se tornou viável apenas na medida em que a comunidade de pesquisa passou a se articular e a advogar pela criação de instrumentos e de instituições que pudessem alavancar o avanço científico e tecnológico nacional. O clima político-ideológico do imediato pós-Segunda Guerra Mundial era inequivocamente favorável à implementação do projeto defendido pela comunidade de pesquisa brasileira, o que também conferia legitimidade a esse discurso. Também aqui no Brasil a ciência era vista como "a fronteira sem fim".

O controle da comunidade de pesquisa sobre a agenda da política científica e tecnológica brasileira foi sendo gradualmente consolidado ao longo do período do Regime Militar, como mostram Motoyama et al. 
(2004). Embora uma parcela considerável dos pesquisadores brasileiros não fosse simpática (implícita ou explicitamente) ao projeto dos militares, a racionalidade da comunidade de pesquisa como um todo não se colocava como um obstáculo: pelo contrário, era funcional a ele. Assim, as políticas de C\&T elaboradas durante esse período eram legitimadas pelo discurso de que a autonomia tecnológica seria uma estratégia fundamental e necessária para a consecução do projeto de desenvolvimento conduzido pelos militares.

A construção de um aparelho estatal de apoio às atividades científicas e tecnológicas relativamente robusto, sobretudo quando comparado àqueles existentes nos demais países da América Latina, foi resultado dos esforços da comunidade de pesquisa brasileira ao longo desse período. As ações conduzidas por esse ator, a partir de então, permitiram a manutenção de seu controle sobre a agenda da PCT, em um processo que pode ser compreendido como a "corporativização" dessa política (Dagnino, 2007).

Ao longo das últimas décadas, nota-se que, a despeito das mudanças mais amplas no âmbito das políticas públicas, decorrentes de processos como a ascensão do neoliberalismo e a Reforma do Estado, a PCT brasileira manteve muitas de suas principais características. Ela se manteve essencialmente "ofertista", ou seja, esteve pautada muito mais na oferta de conhecimento e de profissionais qualificados por parte da academia do que por uma efetiva demanda do setor produtivo. E preservou, ainda, sua motivação "vinculacionista", tendo sido movida pelo imperativo da promoção de laços entre universidades e empresas, mesmo em contextos em que essas relações mostravam-se pouco interessantes para ambos os lados (Dagnino, Thomas \& Davyt, 1996).

Também é um traço bastante forte da PCT brasileira a preocupação para com a emulação de arranjos e práticas observados nos países ditos "desenvolvidos". Os EUA são, nesse sentido, a principal fonte de inspira- 
ção para as medidas adotadas no Brasil. São inúmeras, por exemplo, as tentativas de reprodução de experiências como a do Vale do Silício, sob o rótulo de "parques e polos tecnológicos". Apesar da atenção que atraem, o sucesso de tais iniciativas tem se mostrado questionável. Para quem interessa, de fato, a criação de arranjos dessa natureza? Autores como Gomes (1999) e Silva (2010) têm argumentado no sentido de desmistificar a forma mecanicista por meio da qual é compreendida a relação entre os parques tecnológicos e o desenvolvimento local. Os autores argumentam que essas iniciativas servem muito mais como poderoso instrumento de marketing institucional para as universidades do que propriamente como forma de promoção de desenvolvimento. Afinal, o que de fato mostram as experiências internacionais dessa natureza é que não basta reproduzir a esmo alguns elementos de determinado contexto (no caso, a proximidade entre universidades e empresas) sem que sejam consideradas também as condições do entorno e a dinâmica segundo a qual se relacionam (Gomes, 1999).

Essas características constitutivas da política científica e tecnológica brasileira (ofertismo, vinculacionismo, emulação acrítica de experiências) a diferenciam daquelas implementadas nos países "desenvolvidos" e a aproximam dos padrões observados nos demais países latino-americanos. A manutenção desses padrões ocorre porque, apesar da incorporação, ainda que tímida, de novos atores ao processo decisório da PCT, a agenda dessa política ainda permanece efetivamente sob o controle do mesmo ator, a comunidade de pesquisa. É ela ainda a responsável pela formulação, pela implementação e pela avaliação dessa política.

Foi essa posição hegemônica que ocupa a comunidade de pesquisa no âmbito da PTC brasileira o fator que possibilitou que a essência dessa política se mantivesse estável desde sua institucionalização. É verdade que hoje ela se mostra muito mais sofisticada: elementos como a inovação tecnológica, a competitividade empresarial (e, por indevida extensão, 
nacional) e a figura da empresa privada estão cada vez mais presentes nos documentos oficiais e mesmo nas reflexões acadêmicas sobre política científica e tecnológica (Viotti, 2008). Essa aparente sofisticação do discurso não deve, contudo, ser confundida com uma mudança significativa no conteúdo da política. Ela é, de fato, parte da estratégia (em grande parte, não intencional e inconsciente) da comunidade de pesquisa no sentido de garantir a continuidade. Assim, o discurso mudou para que a agenda da política não tivesse que fazê-lo.

Embora não seja usual na literatura que trata do tema, parece-nos fundamental associar essa postura da comunidade de pesquisa às mudanças que ocorreram na economia e no próprio Estado brasileiro, sobretudo a partir do final da década de 1980. É preciso compreendê-la à luz dos constrangimentos econômicos do período, os quais impuseram fortes restrições aos mecanismos de financiamento público às atividades de C\&T, forçando a comunidade de pesquisa a buscar fontes alternativas de recurso (que, em geral, apontavam para o setor privado).

Essa mudança de postura deve também ser entendida como reflexo do processo de reforma gerencial do Estado, operado no Brasil de forma particularmente intensa a partir da década de 1990. Por um lado, o imperativo do Estado mínimo desferiu um duro golpe contra o complexo público de educação superior e de pesquisa brasileiro. Por outro, ajudou ainda a compor a retórica de cunho neoliberal que pavimentou o caminho para as mudanças no discurso da política científica e tecnológica. Assim, esses processos se mostraram funcionais para a manutenção da posição hegemônica deste ator, ameaçada pelos constrangimentos de ordem econômica que então se verificavam.

Essas reflexões permitem a constatação de que, assim como em qualquer outra política elaborada na esfera do Estado capitalista, a PCT é também uma política que atende aos interesses de determinados atores 
(ou classes sociais) em detrimento daqueles de outros. E também possibilitam o entendimento de que, assim como em outras políticas, o discurso nem sempre reflete claramente o que se pretende fazer na prática. Ele pode ser usado - e de fato o é, com frequência - como uma estratégia de legitimação de determinado projeto político. No caso da política científica e tecnológica, isso se torna razoavelmente mais fácil em decorrência da confiança (ou seria fé?) na ciência, na tecnologia e na opinião dos cientistas. Essa dinâmica, apesar de apresentar algumas peculiaridades no contexto de um país periférico como o Brasil, é bastante próxima daquela que se verifica também nos países ditos "desenvolvidos".

As considerações apresentadas até aqui nos permitem finalmente abordar a questão central proposta neste artigo: o caráter de classe da política científica e tecnológica. Reconhecer que esta - assim como as demais políticas públicas elaboradas no âmbito do Estado capitalista - favorece as classes dominantes constitui uma noção plenamente razoável. Por que, portanto, é tão difícil de se perceber esse traço na PCT? Por que iniciativas que se propõem a estimular a produção e uso de conhecimentos e tecnologias julgados mais adequados às necessidades e às demandas da classe trabalhadora e dos excluídos - notadamente, o recente movimento pela Tecnologia Social - encontram tantas dificuldades em inserir-se na agenda dessa política? Por que não se questiona que recursos públicos sigam financiando atividades científicas e tecnológicas cujos resultados beneficiarão não a sociedade como um todo, mas um conjunto restrito de atores (por exemplo, empresas multinacionais)?

A resposta nos remete à estratégia de blindagem da agenda da PCT, via preservação da condição latente de determinados conflitos. Isso ocorre quando a existência de tais conflitos sequer é percebida pelos atores mais fracos (Lukes, 1974). 
No que se refere à política científica e tecnológica, as próprias concepções essencialistas e triunfalistas acerca de C\&T cumprem o papel de encobrir os conflitos. "A ciência é a representação pura do mundo natural, é a verdade"; "a tecnologia é a aplicação do conhecimento científico"; "ciência, tecnologia e inovação são as forças propulsoras do progresso". Ideias como essas compõem, juntamente com outros elementos, a moldura ideológica que sustenta a posição de prestígio da comunidade de pesquisa (Cozzens \& Gieryn, 1990).

Os "mitos" que encobrem a ciência e a tecnologia e conformam a racionalidade da "fronteira sem fim" (Sarewitz, 1996), brevemente apresentados no segundo item deste artigo, estão na base dessas noções, ainda fortemente arraigadas nas sociedades contemporâneas. Essas ideias dão forma à agenda de pesquisa. Influenciam currículos na educação superior. Conformam estruturas de poder. E moldam a política científica e tecnológica.

Essa racionalidade cria uma particular situação em que potenciais conflitos se tornam latentes pelo não questionamento dos aspectos políticos atrelados a C\&T e à política científica e tecnológica. E o faz, por exemplo, ao excluir qualquer possibilidade de produção de conhecimentos alternativos (afinal, "a ciência é uma só"), ao promover uma separação artificial entre a ciência e as demais esferas que compõem a vida social (afinal, "a ciência compete apenas aos cientistas") e ao aferir à opinião dos cientistas um peso desproporcional nas decisões públicas, inclusive naquelas que não necessariamente competem à ciência (afinal, "os experts é quem decidem").

Essa argumentação possibilita que tomemos os questionamentos propostos por Laswell (1958), que os adaptemos e que os respondamos no que tange especificamente à PCT brasileira. As questões que nos interessam, assim, são: Quais são os atores sociais que participam efetivamente da elaboração dessa política pública? Quais são os que dela se beneficiam? E que diferença isso faz? 
Em relação à primeira dessas perguntas, convém destacar o caráter insular da PCT brasileira. Trata-se de uma política descolada das demandas da ampla maioria dos atores sociais, sendo dominada pela comunidade de pesquisa. Não participam de sua formulação, implementação ou avaliação (ou o fazem ainda de forma absolutamente marginal) outros atores relevantes como, por exemplo, movimentos sociais, ONGs, cooperativas populares, sindicatos e agremiações, etc. É verdade que, sobretudo em democracias ainda imaturas como a brasileira, esse quadro tende a ser comum a todas as políticas públicas. Contudo, o que se observa é que, especificamente no caso da PCT, essa característica é ainda mais notável.

Mecanismos e canais de participação pública têm se difundido ao longo dos últimos anos no Brasil. Experiências envolvendo o orçamento participativo e as grandes conferências temáticas nacionais têm se disseminado. Entretanto, isso ainda não se tornou uma realidade na PCT. O envolvimento de outros atores com a política tem, como apresentado anteriormente, ocorrido apenas no plano simbólico.

Um exemplo disso remete ao Plano de Ação em Ciência, Tecnologia e Inovação para o Desenvolvimento Nacional (2007-2010), que envolve um eixo estratégico (um dos quatro que apresenta), batizado de "Ciência, Tecnologia e Inovação para o Desenvolvimento Social". Esse eixo seria aquele que, ao menos em tese, contemplaria as demandas "sociais" (ou, mais propriamente, pela inclusão social) associadas a C\&T. A "política explícita" (Herrera, 1973), portanto, reconhece a importância e a legitimidade das demandas desses atores. A análise da "política implícita", por outro lado, reforça a percepção de que essas demandas ainda são marginais na esfera da PCT, dado que o volume de recursos destinados a essas ações é irrisório quando comparado àquele destinado às demais (Fonseca, 2009).

Há, ainda, outro ponto que reforça esse argumento. Trata-se da constatação de que as coalizões que historicamente moldaram essa po- 
lítica foram formadas majoritariamente por membros da comunidade de pesquisa. Assim ocorreu quando da criação da Embraer, vinculada à criação de capacidades tecnológicas e produtivas; quando da instituição da Política Nacional da Informática (que mobilizou os cientistas-empresários brasileiros atuando no setor); e também quando da elaboração do Programa de Apoio ao Desenvolvimento Científico e Tecnológico (PADCT), na década de 1980, que favoreceu a formação de "grupos de excelência" em "novas tecnologias".

Essa mesma tendência pôde ainda ser observada na Comissão Técnica Nacional de Biossegurança (CTNBio), responsável pela proposição de uma Política Nacional de Biossegurança, pelo estabelecimento de normas técnicas e regulamentação atreladas a organismos geneticamente modificados e pela emissão de pareceres técnicos. Tait Lima (2009) mostra que a CTNBio é formada quase que exclusivamente por cientistas. Mesmo os "representantes da sociedade civil" que compõem a Comissão têm um perfil densamente acadêmico. A percepção geral é a de que as decisões relativas a temas ligados a ciência e tecnologia cabem aos cientistas. Conforme argumentamos, essa blindagem que reveste a PCT é resultado dos mitos que revestem ciência e tecnologia nas sociedades contemporâneas.

Em relação à segunda pergunta, acerca dos atores que se beneficiam da PCT no Brasil, é possível observar, com base na trajetória dessa política, que a comunidade de pesquisa tem sido, historicamente, o ator que mais tem se beneficiado das ações implementadas no âmbito da PCT. Mais recentemente, contudo, percebe-se que as empresas privadas também passaram a ter acesso a alguns benefícios outorgados por essa política (como os previstos nas leis n $10.973 / 2004$, a "Lei da Inovação", e n 11.196/2005, a "Lei do Bem").

O mesmo não pode ser afirmado em relação à agenda de outros atores, como movimentos sociais e ONGs, política e ideologicamente antagônica em relação à agenda da comunidade de pesquisa em mui- 
tos aspectos. Para que esses atores possam se firmar como importantes na esfera da PCT, devem perseguir estratégias que permitam sensibilizar parcelas relevantes da academia à proposta da tecnologia para a inclusão social. Caso contrário, permanecerão como atores marginais no processo de elaboração dessa política.

Essas reflexões tornam mais simples responder à terceira pergunta que colocamos ("que diferença isso faz?"). Defender a garantia da participação de um conjunto mais diverso e abrangente de atores no processo de elaboração das políticas públicas é um compromisso para com a democracia plena, que transcenda aquela de caráter meramente formal.

Em um país onde grande parte da população está apartada do emprego formal e não tem acesso a uma série de serviços básicos garantidos por lei, não se pode aceitar que ações financiadas pelo dinheiro público sigam beneficiando exclusivamente alguns grupos privilegiados. Ao final, compreender como uma política pública é elaborada é fundamental para seu aprimoramento e para o avanço das práticas democráticas.

\section{Considerações finais}

Neste artigo, exploramos algumas das principais características da política científica e tecnológica. Apresentamos conceitos e definições gerais acerca das políticas públicas para que pudéssemos, posteriormente, avançar à discussão sobre o objeto específico de nosso interesse: a política científica e tecnológica. Mostramos algumas de suas especificidades e abordamos, de forma breve, sua trajetória no contexto brasileiro, evidenciando o significado político de algumas de suas transformações.

Esperamos, conforme salientado na introdução deste artigo, ter abordado os principais aspectos constitutivos da política científica e tecnológica, particularizando alguns deles para o caso brasileiro. 
Nesse sentido, e recuperando alguns dos pontos discutidos anteriormente, caracterizamos a PCT como uma política blindada, de cujo processo de formulação, implementação e avaliação participam, quase que exclusivamente, os cientistas. Outros atores potencialmente interessados nessa política acabam participando apenas de forma marginal nesse processo. A especificidade fundamental que essa blindagem impõe em relação ao que ocorre em outras políticas públicas é que, na PCT, os atores excluídos do processo decisório raramente se dão conta de que $C \& T$ são temas sobre os quais poderiam (e, de fato, deveriam) opinar e decidir.

A peculiaridade da PCT em relação às demais políticas públicas, desse modo, não está no fato de ela ser uma política que acaba por favorecer as classes dominantes (pelo contrário, esse é o ponto que tem em comum com as demais políticas elaboradas no âmbito do Estado capitalista), mas na forma como essa sua característica é ocultada. Ciência e tecnologia - ou, mais propriamente, a percepção fetichizada que se tem delas - cumprem um papel que é funcional à preservação da posição de prestígio da comunidade de pesquisa.

É preciso, portanto, superar essa noção, segundo a qual a ciência e a tecnologia são temas que competem exclusivamente aos cientistas, sobretudo em um mundo em que C\&T se tornam cada vez mais presentes no cotidiano das pessoas, as decisões a respeito desses temas não podem seguir sendo monopólio de um único ator.

\section{What is scientific and technological policy?}

\section{Abstract}

This paper seeks to examine a public policy - science and technology policy (STP) - by debating some of its main characteristics (that distinguish it significantly from the others) and evidencing some of its less discussed aspects: as any policy 
elaborated in the sphere of the capitalist state, STP is, evidently, a class-oriented policy. The paper seeks to understand why this aspect is scarcely recognized. It also discusses some of the main causes and consequences of this aspect. In order to accomplish these goals, it explores some general concepts and definitions regarding public policies. It then discusses the main characteristics and processes associated to science and technology policy, as well as the specificities of Brazilian STP that, to a great extent, shows its class orientation. Lastly, it presents some arguments that seek to explain why this class orientation is not commonly recognized.

Keywords: Science and technology policy. Public policies. Capitalist state. Research community. Brazil.

\section{Referências}

ARRUDA, M.; VERMULM, R.; HOLLANDA, S. Inovação tecnológica no Brasil: a indústria em busca da competitividade global. São Paulo: ANPEI, 2006.

BAUMGARTEN, M. C\&T na semiperiferia e inovação social: desigualdades, excelência e competitividade. In: MACIEL, M. L.; ALBAGLI, S. (Orgs.). Informação e desenvolvimento: conhecimento, inovação e apropriação social. Brasília: UNESCO e IBICT, 2007.

BIMBER, B.; GUSTON, D. H. Politics by the same means: government and science in the United States. In: JASANOFF, S. et al (eds.) Handbook of science and technology studies. Thousand Oaks, EUA: SAGE Publications, 1995.

BOZEMAN, B. Technology and economic development for whom? The prospects for 'dual agenda' state programs. In: TEICH, A. H. et al. (orgs.) AAAS Science and Technology Policy Yearbook 2000. Washington, EUA: American Association for the Advancement of Science, 2000.

BRUGUÉ, Q. Modernizar la administración desde la izquierda: burocracia, nueva gestión pública y administración deliberativa. Revista del CLAD Reforma y Democracia, $n^{\circ} 29,2004$.

CORDER, S.; SALLES FILHO, S. L. Financiamento e incentivos ao Sistema Nacional de Inovação. Parcerias Estratégicas, no 19, p. 129-164, 2004.

COZZENS, S.; GIERYN, T. Theories of science in society. Bloomington, EUA: Indiana University Press, 1990.

DAGNINO, R.; THOMAS, H.; DAVYT, A. El pensamiento en Ciencia, tecnología y sociedad en América Latina: una interpretación política de su trayectoria. REDES

- Revista de Estudios Sociales de la Ciencia, v. 3, no 7, 1996. 
DAGNINO, R. P. Ciência e tecnologia no Brasil: o processo decisório e a comunidade de pesquisa. Campinas: Editora da Unicamp, 2007.

EDELMAN, M. The symbolic uses of politics. Urbana, EUA: University of Illinois Press, 1985.

ERBER, F. S. Perspectivas da América Latina em ciência e tecnologia. In: DOMINGUES, J. M.; MANEIRO, M. (orgs.) América Latina hoje: conceitos e interpretações. Rio de Janeiro: Civilização Brasileira, 2006.

FONSECA, R. R. Política científica e tecnológica para o desenvolvimento social: uma análise do caso brasileiro. Campinas: UNICAMP, 2009. Tese de Doutorado, DPCT/IG, UNICAMP, 2009.

GOMES, E. Polos tecnológicos y promoción del desarrollo: ¿Hecho o Artefacto? REDES - Revista de Estudios Sociales de la Ciencia, vol. 6, no 14, 1999.

FERNANDES, A. M. A construção da ciência no Brasil e a SBPC. Brasília: Editora da UnB, 1990.

HAM, C.; HILL, M. The policy process in the modern capitalist state. Londres, RU: Harvester Wheatsheaf, 1993.

HERRERA, A. O. Los determinantes sociales de la política científica en América Latina - política científica explícita y política científica implícita. Desarrollo Económico, vol. 13, n49.

KRAEMER, S. Science \& Technology Policy in the United States: open systems in action. New Brunswick: Rutgers University Press, 2006.

LASWELL, H.D. Politics: who gets what, when, how. Cleveland, EUA: Meridian Books, 1958.

LUKES, S. Power: a radical view. Londres, RU: Macmillan, 1974.

LYNN, L. E. Designing Public Policy: a casebook on the role of policy analysis. Santa Monica, EUA: Goodyear, 1980.

MACIEL, M. L. Ciência, tecnologia e inovação: idéias sobre o papel das ciências sociais no desenvolvimento. Parcerias Estratégicas, v. 21, p. 33-45, 2005.

MEAD, L. M. "Public Policy: Vision, Potential, Limits". Policy Currents, 1-4, fevereiro de 1995.

MOREL, R. L. M. Ciência e Estado: a política científica no Brasil. São Paulo: T. A. Queiroz, 1979.

MOTOYAMA, S. et al. 1964 - 1985: sob o signo do desenvolvimentismo. In: MOTOYAMA, S. (org.) Prelúdio para uma história: ciência e tecnologia no Brasil. São Paulo: Editora da Universidade Estadual de São Paulo, 2004. 
NEAL, H. A.; SMITH, T. L.; MCCORMICK, J. B. Beyond Sputnik: US science policy in the $21^{\text {st }}$ century. Ann Arbor, EUA: The University of Michigan Press, 2008.

O'DONNELL, G. Anotações para uma teoria do Estado. Revista de Cultura e Política, $n^{\circ} 4,1981$.

OFFE, C. Problemas estruturais do Estado capitalista. Rio de Janeiro: Tempo Brasileiro, 1994.

OSZLAK, O.; O'DONNELL, G. Estado y políticas estatales en América Latina: hacia una estrategia de investigación. REDES - Revista de Estudios Sociales de la Ciencia, vol. 2, no 4, 1995.

PETERS, B. G. American Public Policy. Chatham, EUA: Chatham House, 1986.

ROCHEFORT, D. A.; COBB, R. W. (eds.) The politics of problem definition: shaping the policy agenda. Lawrence, EUA: The University Press of Kansas.

ROTH DEUBEL, A. N. Políticas públicas: formulación, implementación y evaluación. Bogotá, Colômbia: Ediciones Aurora, 2006.

SALOMON, J. J. Science policy and its myths. Diogenes, vol. 18, n 70, 1970.

. Comentarios al dossier: ciencia, la frontera sin fin. REDES - Revista

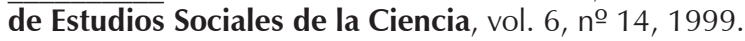

SALOMON, J. J.; LEBEAU, A. Mirages of development: science and technology for the Third Worlds. Londres, RU: Lynne Rienner Publishers, 1993.

SAREWITZ, D. Frontiers of illusion: science, techonology and politics of progress. Filadélfia, EUA: Temple University Press, 1996.

SCHWARTZMAN, S. Pesquisa universitária e inovação no Brasil. In: VELHO, L.; SOUZA PAULA, M. C. (orgs.) Avaliação de políticas de ciência, tecnologia e inovação: diálogo entre experiências internacionais e brasileiras. Brasília: Centro de Gestão e Estudos Estratégicos, 2008.

SILVA, R. B. Polo e parque de alta tecnologia: o Mito de Campinas. Campinas: RG, 2010.

SMITH, B. L. R. American science policy since World War II. Washington, EUA: The Brookings Institution, 1990.

SOBRAL, F. A. F. As ciências humanas e os novos caminhos da política científica e tecnológica. In: SARTI, I. (org.) Ciência, política e sociedade: as ciências sociais na América do Sul. Porto Alegre: UFRGS/SBPC, 2007.

SOUZA, C. Políticas públicas: uma revisão da literatura. Sociologias, Porto Alegre, ano 8, no 16, p. 20-45, 2006. 
SPOSATI, A. Mínimos sociais e seguridade social: uma revolução da consciência da cidadania". Serviço Social e Sociedade, n.55, p. 9-33, 1997.

TAIT LIMA, M. M. As concepções de cientistas brasileiros sobre a tecnociência: um estudo a partir da CTNBio. Campinas, SP: UNICAMP, 2009. Tese de Doutorado, DPCT/IG, UNICAMP, 2009.

THWAITES REY, M. ¿Qué Estado tras el experimento neoliberal? Revista del CLAD Reforma y Democracia, $n^{\circ}$ 41, 2008.

VELHO, L.; VELHO, P. \& SÁENZ, T. P\&D nos setores público e privado no Brasil: complementares ou substitutos?. Parcerias Estratégicas, no 19, p. 87-128, 2004.

VIOTTI, E. B. Brasil: de política de C\&T para política de inovação? Evolução das políticas brasileiras de ciência, tecnologia e inovação. In: VELHO, L.; SOUZA PAULA, M. C. (orgs.). Avaliação de políticas de ciência, tecnologia e inovação: diálogo entre experiências internacionais e brasileiras. Brasília: Centro de Gestão e Estudos Estratégicos, 2008.

Recebido: 11/03/2011

Aceite final: 08/07/2011 